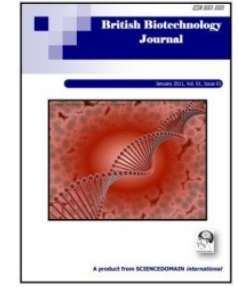

British Biotechnology Journal

4(6): 640-648, 2014

SCIENCEDOMAIN international

www.sciencedomain.org

\title{
Effects of External Carbon Source Concentration on Sulphate Removal by Selected Bacterial and Fungal species
}

\author{
O. B. Akpor ${ }^{1^{\star}}$, S. O. Dahunsi ${ }^{1}$ and R. Aransiola ${ }^{2}$ \\ ${ }^{1}$ Microbiology Unit, Department of Biological Sciences, Landmark University, PMB 1001, \\ Omu Aran, Kwara State, Nigeria. \\ ${ }^{2}$ Department of Biochemistry, University of Ilorin, Kwara State, Nigeria.
}

\begin{abstract}
Authors' contributions
This work was carried out in collaboration between all authors. Author OBA conceptualized and designed the study, was involved in the laboratory analysis and wrote the first draft of the manuscript. Author SOD was involved in the laboratory analysis, carried out literature search, assisted in the interpretation of some of the results and proof read the first draft of the manuscript. Author RA was involved in the design of the experiment, carried out laboratory analysis and proof read the first draft of the manuscript. All authors read and approved the final manuscript.
\end{abstract}

Original Research Article

Received $3^{\text {rd }}$ April 2014

Accepted $12^{\text {th }}$ May 2014

Published 22 ${ }^{\text {nd }}$ May 2014

\section{ABSTRACT}

The aim of this study was to investigate the role of initial external carbon source concentration on sulphate removal by four bacterial and four fungal isolates under shake flask conditions. The test wastewater was filtered and supplemented with sodium acetate as the external carbon source at respective concentrations of $5 \mathrm{~g} / \mathrm{L}, 10 \mathrm{~g} / \mathrm{L}, 15 \mathrm{~g} / \mathrm{L}$ and $20 \mathrm{~g} / \mathrm{L}$, before dispensing in $200 \mathrm{~mL}$ quantity in $250 \mathrm{~mL}$ capacity conical flasks, sterilised and inoculated with the test microbial isolates. Prior inoculation and at $24 \mathrm{~h}$ interval, for 96 $\mathrm{h}$ for the estimation of sulphate concentration in the wastewater using standard methods. The results revealed remarkable sulphate removal in the absence of the sodium acetate and on its $5 \mathrm{~g} / \mathrm{L}$ addition. An increase in the concentration of the sodium acetate caused a corresponding decrease in the level of sulphate removal. Percentage sulphate removals in presence of the test isolates were observed to range from 47.01 to $57.81 \%, 18.66$ to $51.66 \%,-1.64$ to $11.03 \%, 5,38$ to $22.37 \%$ and -3.59 to $5.18 \%$, at sodium acetate concentrations of $0 \mathrm{~g} / \mathrm{L}, 5 \mathrm{~g} / \mathrm{L}, 10 \mathrm{~g} / \mathrm{L}, 15 \mathrm{~g} / \mathrm{L}$ and $20 \mathrm{~g} / \mathrm{L}$, respectively. This trend was 
irrespective of the isolates used for investigation. The study was able to provide an insight to the role of carbon concentration on sulphate removal by the test microbial isolates.

Keywords: Carbon source; sulphate removal; wastewater; bacteria, fungi.

\section{INTRODUCTION}

Several inorganic anions (carbonates, chlorides, sulphates and nitrates) and cations (sodium, potassium, calcium and magnesium) are known to be dissolved in water. Sulphate, which is a constituent of the total dissolved solids may form salts with sodium, potassium, magnesium and other cations. It is widely distributed in nature and may be present in natural waters at concentrations ranging from a few to several hundred milligrams per liter. The anthropogenic sources of sulphate may come from mine drainage wastes through pyrite oxidation, reverse osmosis reject water, cooling tower blow down among others [1].

Although sulphate is indicated to be one of the least toxic anions with lethal dose of $45 \mathrm{~g}$ for humans as potassium or zinc salt and $200 \mathrm{mg} / \mathrm{kg}$ for magnesium sulphate in mammals. Individuals consuming water containing sulphate in concentrations exceeding $600 \mathrm{mg} / \mathrm{L}$ are indicated to experience cathartic effects, resulting in purgation of the alimentary canal. Also, dehydration has also been reported as a common side effect that follows the ingestion of large amounts of sodium or magnesium sulphate. The test threshold concentrations for most sulphate salts are indicated to range between 250 and $500 \mathrm{mg} / \mathrm{L}$ [2].

There is an increasing interest in the potential biotechnological applications of microbial sulfate reduction as an alternative method for sulfate and heavy metal removal from environmental contaminated sources [3]. When sulphate is reduced to sulphide, a carbon and energy source is needed, which functions as the electron donor. It is reported that biochemically, the reduction of sulphate is coupled to the formation of an energy-containing compound called Adenosine Triphosphate (ATP), by a proton motive force. The sulphate is reduced in a stepwise fashion to hydrogen sulphide gas by intracellular enzymes, thus necessitating the transport of the sulphate from the external environment by active transport, involving ATP expenditure. The sulphate inside the cell is then reduced to sulphite and hydrogen sulphide gas by a collection of enzymes [4].

Although both chemical and biological methods are used for the removal of sulphate from wastewaters in the past years, attention has moved away from the traditional chemical treatment to the biological treatment, provided a suitable carbon source, such as lactic acid, acetate and other volatile fatty acids are available. The availability of carbon is therefore indicated to form a critical limiting factor for microbial activity during biological sulphate removal $[5,6]$. The aim of this study was to investigate the effect of an external carbon source concentration on the sulphate removal ability of selected bacterial and fungal species.

\section{MATERIALS AND METHODS}

\subsection{Source of Material}

The wastewater used for this study was sampled from the Landmark University Commercial Farms, located in Omu Aran, Kwara State, Nigeria. Before usage, the water was filtered into 
$250 \mathrm{~mL}$ conical flasks, using Whatman No 1 filter paper. The filtered water in each of the flasks was supplemented with a known concentration of sodium acetate (to serve as an external carbon source), peptone $(2.5 \mathrm{~g} / \mathrm{L})$ and magnesium sulphate $(0.5 \mathrm{~g} / \mathrm{L})$. The flasks were then cotton plugged with non-absorbent cotton wool and then sterilised in an autoclave.

\subsection{Test Isolates}

The test organisms used for the study consisted of four fungal (Aspergilllus niger, Aspergillus flavus, Fusarium sp. and Absidia sp.) and four bacterial (Pseudomonas sp., Klebsiella sp., Staphylococcus sp. and Lysinibacillus sp.) species. The isolates were obtained from the laboratory stock of the Department of Microbiology, Ekiti State University, Ado Ekiti in Nigeria. The isolates were first plated out on agar (nutrient agar for the bacteria and potato dextrose agar for the fungi) to ascertain their purity, after which they were maintained on agar slants before refrigerating at $4^{\circ} \mathrm{C}\left( \pm 2^{\circ} \mathrm{C}\right)$ until needed.

\subsection{Experimental Procedure}

Five different experimental groups were investigated for each test isolate including wastewater media that contain $0 \mathrm{~g} / \mathrm{L}, 5 \mathrm{~g} / \mathrm{L}, 10 \mathrm{~g} / \mathrm{L}, 15 \mathrm{~g} / \mathrm{L}$ and $20 \mathrm{~g} / \mathrm{L}$ sodium acetate respectively. For sulphate uptake studies, the test isolates were first inoculated into normal saline $(0.85 \% \mathrm{NaCl}$ in distilled water $\mathrm{w} / \mathrm{v})$ before adding $1 \mathrm{~mL}$ of the cultures in the flasks. The I mL cultures used for inoculation, corresponded to $7.50 \times 10^{2}$ spores $/ \mathrm{mL}$ for the Aspergillus niger; $3.6 \times 10^{3}$ spores $/ \mathrm{mL}$ for the Aspergillus flavus, $1.16 \times 10^{3}$ spores $/ \mathrm{mL}$, for the Absidia sp., $2.80 \times 10^{2}$ spores $/ \mathrm{mL}$ for the Fusarium sp., $2.91 \times 10^{8} \mathrm{cfu} / \mathrm{mL}$, for the Klebsiella sp., $6.31 \times 10^{8} \mathrm{cfu} / \mathrm{mL}$ for the Pseudomonas sp., $1.75 \times 10^{8} \mathrm{cfu} / \mathrm{mL}$ for the Lysinibacillus sp. and $7.1 \times 10^{8} \mathrm{cfu} / \mathrm{mL}$ for the Staphylococcus sp.

After inoculation with the test isolates, the flasks were incubated in a shaker incubator at a temperature of $30^{\circ} \mathrm{C}$ and a shaking speed for $150 \mathrm{rpm}$ for $96 \mathrm{~h}$. Immediately after inoculation and at $24 \mathrm{~h}$ interval, for the next $96 \mathrm{~h}$, aliquot wastewater sample was aseptically taken from each flasks for the estimation of sulphate concentration in the wastewater, using standard procedures [7]. In all groups of experiments, an uninoculated control was also set up while all experimental analyses were carried out in triplicate. All the reagents used for the study were of analytical grade.

\section{RESULTS AND DISCUSSION}

As shown in Table 1, at $0 \mathrm{~g} / \mathrm{L}$ of sodium acetate in the test wastewater medium, there was consistent decrease in sulphate concentration with time. This trend was irrespective of the isolates used in the investigation. At the end of the $96 \mathrm{~h}$ incubation period, sulphate uptake by the test isolates ranged from 41.90 to $68.91 \%$, with minimum and maximum uptakes observed in the presence of the Absidia sp. and Pseudomonas sp., respectively.

In the presence of the test isolates, remarkable decreases in sulphate concentrations in the wastewater were observed after $72 \mathrm{~h}$ incubation, after which there were increases in concentration. This trend was irrespective of the test isolates. At the expiration of the incubation, the level of uptake of the sulphate in the wastewater among the test isolates ranged from 18.66 to $51.66 \%$, with the lowest and highest uptake observed in the presence of the Staphylococcus and the Lysinibacillus species (Table 2). 
Table 1. Sulphate concentration in presence of the test isolates at $0 \mathrm{~g} / \mathrm{L}$ of sodium acetate in the test medium

\begin{tabular}{lllllll}
\hline Test isolates & $\mathbf{O h}$ & $\mathbf{2 4 h}$ & $\mathbf{4 8 h}$ & $\mathbf{7 2 h}$ & $\mathbf{9 6 h}$ & \% decrease \\
\hline Aspergillus niger & 790.62 & 728.29 & 504.38 & 395.88 & 334.71 & 57.66 \\
& $( \pm 2.00)$ & $( \pm 2.00)$ & $( \pm 4.00)$ & $( \pm 8.71)$ & $( \pm 2.00)$ & \\
Aspergillus flavus & 790.62 & 690.20 & 533.23 & 290.85 & 418.97 & 47.01 \\
& $( \pm 2.00)$ & $( \pm 5.29)$ & $( \pm 3.46)$ & $( \pm 3.46)$ & $( \pm 3.24)$ & \\
Fusarium sp. & 790.62 & 727.14 & 672.89 & 362.41 & 279.31 & 64.67 \\
& $( \pm 2.00)$ & $( \pm 6.00)$ & $( \pm 4.00)$ & $( \pm 2.00)$ & $( \pm 2.00)$ & \\
Absidia sp. & 790.62 & 683.28 & 667.12 & 392.42 & 459.36 & 41.90 \\
& $( \pm 2.00)$ & $( \pm 10.58)$ & $( \pm 2.00)$ & $( \pm 2.00)$ & $( \pm 5.29)$ & \\
Pseudomonas sp. & 790.62 & 659.04 & 548.24 & 475.52 & 245.84 & 68.91 \\
& $( \pm 2.00)$ & $( \pm 2.00)$ & $(2.00)$ & $(2.00)$ & $( \pm 3.46)$ & \\
Klebsiella sp. & 790.62 & 738.68 & 662.50 & 335.87 & 253.92 & 67.88 \\
& $( \pm 2.00)$ & $( \pm 2.00)$ & $( \pm 5.29)$ & $( \pm 6.93)$ & $( \pm 10.58)$ & \\
Staphylococcus & 790.62 & 777.92 & 694.82 & 460.52 & 375.11 & 52.55 \\
sp. & $( \pm 2.00)$ & $( \pm 2.00)$ & $( \pm 7.21)$ & $( \pm 3.46)$ & $( \pm 2.00)$ & \\
Lysinibacillus sp. & 790.62 & 807.93 & 977.59 & 447.82 & 333.56 & 57.81 \\
& $( \pm 2.00)$ & $( \pm 2.00)$ & $( \pm 8.71)$ & $( \pm 2.00)$ & $( \pm 4.00)$ & \\
Control & 790.62 & 801.34 & 786.58 & 780.42 & 768.54 & 2.79 \\
& $( \pm 2.00)$ & $( \pm 3.24)$ & $( \pm 5.32)$ & $( \pm 4.00)$ & $( \pm 3.64)$ & \\
\hline
\end{tabular}

All values are averages of triplicate analysis. Values in parenthesis are \pm the standard deviations

Table 2. Sulphate concentration in presence of the test isolates at $5 \mathrm{~g} / \mathrm{L}$ of sodium acetate in the test medium

\begin{tabular}{lllllll}
\hline Test isolates & $\mathbf{O h}$ & $\mathbf{2 4 h}$ & $\mathbf{4 8 h}$ & $\mathbf{7 2 h}$ & $\mathbf{9 6 h}$ & \% decrease \\
\hline Aspergillus niger & 790.62 & 814.85 & 625.57 & 590.94 & 599.02 & 24.23 \\
& $( \pm 4.00)$ & $( \pm 2.00)$ & $( \pm 11.13)$ & $( \pm 8.00)$ & $( \pm 3.46)$ & \\
Aspergillus flavus & 790.62 & 829.86 & 543.62 & 547.08 & 612.87 & 22.48 \\
& $( \pm 4.00)$ & $( \pm 2.00)$ & $( \pm 6.00)$ & $( \pm 3.46)$ & $( \pm 17.99)$ & \\
Fusarium sp. & 790.62 & 708.67 & 480.14 & 347.41 & 512.46 & 35.18 \\
& $( \pm 4.00)$ & $( \pm 13.99)$ & $( \pm 5.29)$ & $( \pm 11.13)$ & $( \pm 3.46)$ & \\
Absidia sp. & 790.62 & 863.33 & 521.69 & 448.98 & 605.95 & 32.36 \\
Pseudomonas sp. & $( \pm 4.00)$ & $( \pm 5.29)$ & $( \pm 5.29)$ & $( \pm 12.16)$ & $( \pm 3.46)$ & \\
& 790.62 & 759.45 & 550.55 & 433.97 & 572.47 & 28.59 \\
Klebsiella sp. & $( \pm 4.00)$ & $( \pm 12.16)$ & $( \pm 3.46)$ & $( \pm 4.00)$ & $( \pm 5.29)$ & \\
& 790.62 & 804.47 & 511.30 & 438.59 & 579.40 & 27.72 \\
Staphylococcus sp. & $( \pm 4.00)$ & $( \pm 15.99)$ & $( \pm 5.29)$ & $( \pm 4.00)$ & $( \pm 7.21)$ & \\
& 790.62 & 780.23 & 528.62 & 495.14 & 650.96 & 18.66 \\
Lysinibacillus sp. & $( \pm 4.00)$ & $( \pm 11.13)$ & $( \pm 3.84)$ & $( \pm 3.46)$ & $( \pm 12.48)$ & \\
& 790.62 & 772.15 & 495.14 & 469.75 & 390.11 & 51.66 \\
Control & $( \pm 4.00)$ & $( \pm 6.93)$ & $( \pm 3.46)$ & $( \pm 5.29)$ & $( \pm 8.71)$ & \\
& 790.62 & 779.62 & 800.22 & 770.56 & 772.65 & $2.27 \%$ \\
\hline
\end{tabular}

All values are averages of triplicate analysis. Values in parenthesis are \pm the standard deviations

Table 3 shows the variation in sulphate concentration in the wastewater supplemented with $10 \mathrm{~g} / \mathrm{L}$ of the external carbon source. The majority of the test isolates showed very minute or no removal of sulphate in the wastewater. Only two of the isolates (Aspergillus niger and Klebsiella sp.) showed a sulphate decrease of over $10 \%$ at the expiration of the incubation 
period. Two of the isolates (Aspergillus flavus and Lysinibacillus sp.) were however observed to show an increase in sulphate concentration at the expiration of incubation.

Table 3. Sulphate concentration in presence of the test isolates at $10 \mathrm{~g} / \mathrm{L}$ of sodium acetate in the test medium

\begin{tabular}{lllllll}
\hline Test isolates & $\mathbf{O h}$ & $\mathbf{2 4 h}$ & $\mathbf{4 8 h}$ & $\mathbf{7 2 h}$ & $\mathbf{9 6 h}$ & \% decrease \\
\hline Aspergillus niger & 774.46 & 837.94 & 657.88 & 736.37 & 655.58 & 15.35 \\
& $( \pm 2.00)$ & $( \pm 3.46)$ & $( \pm 6.00)$ & $( \pm 8.71)$ & $( \pm 16.36)$ & \\
Aspergillus flavus & 774.46 & 758.30 & 559.78 & 579.40 & 788.31 & -1.79 \\
& $( \pm 2.00)$ & $( \pm 3.46)$ & $( \pm 5.29)$ & $( \pm 7.21)$ & $( \pm 15.61)$ & \\
Fusarium sp. & 774.46 & 837.94 & 653.27 & 631.34 & 738.68 & 4.62 \\
& $( \pm 2.00)$ & $( \pm 13.85)$ & $( \pm 2.00$ & $( \pm 2.00)$ & $( \pm 5.29)$ & \\
Absidia sp. & 774.46 & 853.36 & 564.40 & 631.34 & 750.22 & 3.13 \\
Pseudomonas sp. & $( \pm 2.00)$ & $( \pm 2.00)$ & $( \pm 3.46)$ & $( \pm 5.29)$ & $( \pm 10.00)$ & \\
& 774.46 & 844.12 & 559.78 & 625.57 & 751.37 & 2.98 \\
Klebsiella sp. & $( \pm 2.00)$ & $( \pm 16.36)$ & $( \pm 4.00$ & $( \pm 4.00)$ & $( \pm 15.09)$ & \\
& 774.46 & 775.61 & 505.53 & 556.32 & 689.05 & 11.03 \\
Staphylococcus sp. & $( \pm 2.00)$ & $( \pm 10.39)$ & $( \pm 12.48)$ & $( \pm 13.11)$ & $( \pm 6.00$ & \\
& 774.46 & 795.23 & 660.19 & 488.22 & 754.84 & 2.53 \\
Lysinibacillus sp. & $( \pm 2.00)$ & $( \pm 8.71)$ & $( \pm 4.00)$ & $( \pm 6.93)$ & $( \pm 3.46)$ & \\
& 774.46 & 887.57 & 513.61 & 601.33 & 787.15 & -1.64 \\
Control & $( \pm 2.00)$ & $( \pm 8.71)$ & $( \pm 4.00)$ & $( \pm 5.29)$ & $( \pm 8.71)$ & \\
& 774.46 & 782.46 & 794.46 & 770.46 & 765.36 & 1.18 \\
\hline
\end{tabular}

All values are averages of triplicate analysis. Values in parenthesis are \pm the standard deviations. Negative values represent increases

At $15 \mathrm{~g} / \mathrm{L}$ concentration of the sodium acetate, the decrease in sulphate concentration in the wastewater in presence of the test isolates was observed to range from 5.38 to $23.37 \%$, with the lowest and highest decrease observed in the presence of the Absidia and Fusarium species, respectively. In the presence of the Aspergillus niger, remarkable decrease in concentration was observed during the 48 and $72 \mathrm{~h}$ of incubation, decreasing from an initial concentration of $944.12 \mathrm{mg} / \mathrm{L}$ at $0 \mathrm{~h}$ to $557.47 \mathrm{mg} / \mathrm{L}$ and $587.48 \mathrm{mg} / \mathrm{L}$, at $48 \mathrm{~h}$ and $72 \mathrm{~h}$, respectively (Table 4).

As shown in Table 5 , sulphate reduction in the wastewater at $20 \mathrm{~g} / \mathrm{L}$ of the sodium acetate in presence of the isolates showed extremely low decreases at the expiration of incubation. Two of the test isolates (Aspergillus flavus and Fusarium sp.) showed slight increases in concentration at the end of incubation. Generally, the decrease in sulphate concentration among the test isolates was observed to range from 1.99 to $5.18 \%$, with the highest and lowest decreases observed in the presence of the Staphylococcus sp. and Lysinibacillus sp., respectively.

The external carbon source used for this investigation was sodium acetate. The choice of acetate was deliberate. It has been reported previously that during biological sulphate removal, synthetic small molecular weight organic compounds like lactate, acetate, propionate, pyruvate and butyrate, ethanol and other alcohols can serve as ideal electron donors $[6,8]$. It is indicated that sulphate reducing bacteria competes with methaneproducing bacteria for substrates, such as hydrogen and acetate and with acetogenic bacteria for intermediate substrates such as short-chain fatty acids and alcohols [9]. 
As seen in this study, carbon source and metabolic activities of sulphate reducing bacteria is said to be diverse, the energy for their growth and maintenance is provided by the carbon source, so as to carry out sulphate reduction agreeing with the submission of Bharati and Kumar [6]. A number of earlier researchers have investigated biological sulphate reduction. In a study by Middleton and Lawrence, [10] in the determination of the kinetics of microbial sulphate reduction using acetic acid as carbon source in a complete mix reactor, although biomass concentration was not specified, a sulphate reduction rate of $0.29 \mathrm{~g}$ sulphate per litre per day was observed [11].

Table 4. Sulphate concentration in presence of the test isolates at $15 \mathrm{~g} / \mathrm{L}$ of sodium acetate in the test medium

\begin{tabular}{lllllll}
\hline Test isolates & $\mathbf{O h}$ & $\mathbf{2 4 h}$ & $\mathbf{4 8 h}$ & $\mathbf{7 2 h}$ & $\mathbf{9 6 h}$ & \% decrease \\
\hline Aspergillus niger & 944.12 & 765.22 & 557.47 & 587.48 & 739.83 & 21.64 \\
& $( \pm 2.00)$ & $( \pm 9.16)$ & $( \pm 3.46)$ & $( \pm 2.00)$ & $( \pm 4.00)$ & \\
Aspergillus flavus & 944.12 & 758.30 & 607.10 & 647.50 & 759.45 & 19.56 \\
& $( \pm 2.00)$ & $( \pm 6.00$ & $( \pm 5.29)$ & $( \pm 3.46)$ & $( \pm 8.71)$ & \\
Fusarium sp. & 944.12 & 765.22 & 783.69 & 594.40 & 732.91 & 22.37 \\
& $( \pm 2.00)$ & $( \pm 9.16)$ & $( \pm 5.29)$ & $( \pm 4.00)$ & $( \pm 13.99)$ & \\
Absidia sp & 944.12 & 767.53 & 755.99 & 795.23 & 893.34 & 5.38 \\
& $( \pm 2.00)$ & $( \pm 12.16)$ & $( \pm 7.21)$ & $( \pm 2.00)$ & $( \pm 3.46)$ & \\
Pseudomonas sp. & 944.12 & 832.17 & 788.31 & 811.39 & 822.93 & 12.84 \\
& $( \pm 2.00)$ & $( \pm 4.00)$ & $( \pm 13.11)$ & $( \pm 4.00)$ & $( \pm 5.29)$ & \\
Klebsiella sp. & 944.12 & 754.84 & 627.88 & 653.27 & 819.47 & 13.20 \\
& $( \pm 2.00)$ & $( \pm 6.00)$ & $( \pm 11.13)$ & $( \pm 2.00)$ & $( \pm 12.16)$ & \\
Staphylococcus sp. & 944.12 & 695.97 & 818.32 & 589.79 & 854.10 & 9.54 \\
Lysinibacillus sp. & $( \pm 2.00)$ & $( \pm 9.16)$ & $( \pm 5.29)$ & $( \pm 2.00)$ & $( \pm 8.71)$ & \\
& 944.12 & 761.76 & 822.93 & 603.64 & 805.62 & 14.67 \\
Control & $( \pm 2.00)$ & $( \pm 9.16)$ & $( \pm 8.71)$ & $( \pm 10.00)$ & $( \pm 22.53)$ & \\
& 944.12 & 950.25 & 952.36 & 946.23 & 948.89 & -0.51 \\
\hline
\end{tabular}

All values are averages of triplicate analysis. Values in parenthesis are \pm the standard deviations. Negative values represent increases. Negative values represent increases

The choice of the isolates was for the investigation was also deliberate. They have previously been implicated to have high ability to remove phosphates and nitrates $[12,13]$. Furthermore, the four test bacterial isolates used for the study were isolated from domestic wastewater sources and have previously been reported to be highly effective in the degradation of dietary oil substrate in wastewater [14], hence exploring their potential for sulphate removal in wastewater systems could further reveal their bioremediation potential. In addition, although the commonest sulphate reducing bacteria are Desulfovibrio desulfuricans, Desulfovibrio vulgaris and Desulfovibrio gigas, other bacteria have been implicated for sulphate reduction in wastewaters. In a study by Mullick [15] on simultaneous removal of sulphate and chromium from tannery waste using microbes, Micrococcus yunanensis and Pseudomonas aeruginosa were reported to remediate about $24 \%$ of sulphate from tannery wastewater at an initial sulphate concentration of $280 \mathrm{mg} / \mathrm{L}$ and 200 $\mathrm{mg} / \mathrm{L}$ respectively. In the same study, and in the presence of a consortium of Desulfovibrio desulfuricans, Desulfovibrio vulgaris and Desulfovibrio gigas in a wastewater that utilized chromium (iv) as the electron acceptor, sulphate decrease from 200 to $70.2 \mathrm{mg} / \mathrm{L}$, translating to $63.9 \%$ decrease observed [15]. Also, the potential of fungi for bioremediation of wastewater pollutants has been advocated. Fungi are said to possess the inherent ability to effectively degrade complex pollutants and produce high value biomass in return $[16,17]$. 
Table 5. Sulphate concentration in presence of the test isolates at $20 \mathrm{~g} / \mathrm{L}$ of sodium acetate in the test medium

\begin{tabular}{lllllll}
\hline Test isolates & $\mathbf{0 h}$ & $\mathbf{2 4 h}$ & $\mathbf{4 8 h}$ & $\mathbf{7 2 h}$ & $\mathbf{9 6 h}$ & \% decrease \\
\hline Aspergillus niger & 869.10 & 760.61 & 677.51 & 891.03 & 836.78 & 3.72 \\
& $( \pm 6.00)$ & $( \pm 5.29)$ & $( \pm 2.00)$ & $( \pm 7.21)$ & $( \pm 5.29)$ & \\
Aspergillus flavus & 869.10 & 817.58 & 891.36 & 852.94 & 882.95 & -1.59 \\
& $( \pm 6.00)$ & $( \pm 9.16)$ & $( \pm 8.71)$ & $( \pm 2.00)$ & $( \pm 21.06)$ & \\
Fusarium sp. & 869.10 & 719.06 & 755.99 & 822.93 & 900.26 & -3.59 \\
& $( \pm 6.00)$ & $( \pm 5.29)$ & $( \pm 5.29)$ & $( \pm 4.00)$ & $( \pm 6.00)$ & \\
Absidia sp. & 869.10 & 872.15 & 813.29 & 824.74 & 844.79 & 2.80 \\
& $( \pm 6.00)$ & $( \pm 6.93)$ & $( \pm 3.46)$ & $( \pm 13.11)$ & $( \pm 8.71)$ & \\
Pseudomonas sp. & 869.10 & 806.77 & 728.29 & 552.85 & 847.17 & 2.52 \\
& $( \pm 6.00)$ & $( \pm 11.99)$ & $( \pm 5.29)$ & $( \pm 7.2) 1$ & $( \pm 15.61)$ & \\
Klebsiella sp. & 869.10 & 878.33 & 727.14 & 461.67 & 850.63 & 2.12 \\
& $( \pm 6.00)$ & $( \pm 11.13)$ & $( \pm 3.46)$ & $( \pm 5.29)$ & $( \pm 10.58)$ & \\
Staphylococcus sp. & 869.10 & 839.09 & 895.65 & 605.95 & 824.09 & 5.18 \\
& $( \pm 6.00)$ & $( \pm 4.00)$ & $( \pm 2.00)$ & $( \pm 4.03)$ & $( \pm 15.09)$ & \\
Lysinibacillus sp. & 869.10 & 826.40 & 738.68 & 832.17 & 851.79 & 1.99 \\
& $( \pm 6.00)$ & $( \pm 13.99)$ & $( \pm 2.00)$ & $( \pm 5.29)$ & $( \pm 3.46)$ & \\
Control & 869.10 & 860.43 & 855.56 & 850.34 & 852.89 & 1.87 \\
& $( \pm 6.00)$ & $( \pm 4.56)$ & $( \pm 4.68)$ & $( \pm 8.42)$ & $( \pm 10.25)$ & \\
\hline
\end{tabular}

All values are averages of triplicate analysis. Values in parenthesis are \pm the standard deviations.

Negative values represent increases

The present study revealed maximum sulphate removal in the absence of the sodium acetate in the wastewater. In the presence of sodium acetate, high sulphate removal was observed at low concentrations of the sodium acetate. This trend was observed in the presence of all the test bacterial and fungal strains used for the investigation. It is indicated that the presence of adequate quantity of electron donors is essential for biological treatment of sulfate rich wastewater as 1 mole of sulfate for the complete reduction requires 0.67 moles of chemical oxygen demand (COD) stoichiometrically. For wastewaters that are rich in sulphate with a high COD or organic, an external electron source is reported not to be essential as the same can be utilized as electron donors but for COD deficient wastewaters, the addition of external carbon sources is said to be a must in order to achieve complete reduction [6].

In this investigation, all the isolates were used as pure cultures, rather than as consortium. The importance of using single cultures in sulphate removal investigation has been reported earlier. In a study by Kantachote et al. [18] on sulfide removal in sulphate-rich wastewater, the test bacterium was observed to be better at removing all forms of the sulfide than when present together with other indigenous microbes. This was attributed to be the likelihood of competition for some essential nutrients with other indigenous microbes which are less effective in sulfide oxidation. The present study was carried out at a temperature of $30 \pm 2^{\circ} \mathrm{C}$ at $\mathrm{pH} 7 \pm 0.2$. Previous investigators have carried out similar studies, using similar conditions $[18,19]$. In a study by Luptakova et al. [19] on bacterial elimination of sulphates from mine waters, the experimental conditions were set an initial $\mathrm{pH}$ of 7.5 at a temperature of $30^{\circ} \mathrm{C}$.

\section{CONCLUSION}

This study which was aimed at investigating the effect of initial carbon source concentration on sulphate removal by the test bacterial and fungal isolates showed all the test isolate 
having the ability to cause reduction in sulphate concentration in wastewater under the experimental conditions investigated. Also, sulphate reduction by the isolates was dependent on the initial carbon source concentration added to the test wastewater medium used for investigation. In addition, remarkable sulphate reduction was observed in the absence and at low initial carbon source concentration. The present study was able to give an insight to the role of initial carbon source on sulphate removal by the test microbial species.

\section{COMPETING INTERESTS}

Authors have declared that no competing interests exist.

\section{REFERENCES}

1. Iowa DNR. Water quality standards review: chloride, sulfate and total dissolved solids. lowa Department of Natural Resources Consultation Package; 2009.

2. INAP. Treatment of sulphates in wastewater. International Network for Acid Prevention (INAP); 2003.

3. Al-Zuhair S, El-Nass M, Al-Hassani H. Sulfate inhibition effect on sulphate reducing bacteria. Journal of Biochemistry and Technology. 2008;1(2):39-44.

4. Eloff, E, Greben HA, Maree JP, Radebe BV, Gomes RE. Biological sulphate removal using hydrogen as the energy source. 8th International Congress on Mine Water \& the Environment, Johannesburg, South Africa; 2003.

5. Greben HA, Maree JP, Mnqanqeni S. Comparison between sucrose, ethanol and methanolas carbon and energy sources for biological sulphate reduction. Water Science and Technology. 2000;4912:247-253.

6. Bharati B, Kumar GP. A study on efficiency of five different carbon sources on sulfate reduction. Journal of Environmental Research and Development. 2012;7(1):416-420.

7. APHA. Standard Methods for the Examination of Water and Wastewater, $22^{\text {nd }}$ edition. APHA, Washington D.C.; 2012.

8. Harada H, Uemura S, Momonoi K. Interaction between sulfate-reducing bacteria and methane-producing bacteria in UASB reactors fed with low strength wastes containing different levels of sulfate, Water Research. 1994;28(1):355-367.

9. Annachhatre AP, Suktrakoolvait S. Biological sulfate reduction using molasses as a carbon source. Water Environment Research. 2001;73(1):118-126.

10. Middleton AC, Lawrence AW. Kinetics of microbial sulphate reduction. Journal of Water Pollution Control Federation. 1977;49(7):1659-1670.

11. Maree JP, Gerber A, Strydom WF. A biological process for sulphate removal from industrial effluents. Water SA. 1986;12(3):139-144.

12. Adelani-Akande TA, Akpor OB, Aderiye BI. Investigation of the role of selected fungal strains in the removal of phosphate and nitrate in synthetic wastewater. Annual Research and Review in Biology. 2014;4(7):1045-1058.

13. Akpor OB, Olaolu TD, Okolie CE. The effect of temperature on nitrate and phosphate uptake from synthetic wastewater by selected bacteria species. British Microbiology Research Journal. 2014;4(3):328-342.

14. Odeyemi AT, Aderiye BI, Bamidele OS. Lipolytic activity of some strains of Klebsiella, Pseudomonas and Staphylococcus spp. from restaurant wastewater and receiving stream. Journal of Microbiology Research. 2013;3(1):43-52. 
15. Mullick U. Simultanoeus removal of sulphate and chromium from tannery waste using microbes. A Master of Technology in Chemical Engineering Thesis, National Institute of Technology, Rourkela-769008; 2012.

16. Jasti N, Khanal SK, Pometto III AL, van Leeuwen J. Fungal treatment of corn processing wastewater in an attached growth system. Water Practice and Technology. 2008;1(3):115-122.

17. Van Leeuwen J, Rasmussen MI, Sankaran S, Koza CR, Erickson DT, Mitra D, Jin B. Fungal treatment of crop processing wastewaters with value-added co-products. In: sutainable bioenergy and bioproducts, green energy and technology (Gopalakrishman K. et al (eds.). Springer-Verlag, London; 2012.

18. Kantachote D, Charernjiratrakul W, Noparatnaraporn N, Oda K. Selection of sulfur oxidizing bacterium for sulfide removal in sulfate rich wastewater to enhance biogas production. Electronic Journal of Biotechnology. 2008;11(2):1-12.

19. Luptakova A, Kotulicova I, Macingova E, Jencarova j. Bacteria elimination of sulphates from mine waters. Chemical Engineering Transactions. 2013;35:853-858.

(C) 2014 Akpor et al.; This is an Open Access article distributed under the terms of the Creative Commons Attribution License (http://creativecommons.org/licenses/by/3.0), which permits unrestricted use, distribution, and reproduction in any medium, provided the original work is properly cited.

Peer-review history:

The peer review history for this paper can be accessed here: http://www.sciencedomain.org/review-history. $p h p ? i i d=538 \& i d=11 \&$ aid $=4650$ 